\title{
THE USE OF OZONIZED OIL IN THE TREATMENT OF DERMATOPHITOSIS CAUSED BY MICROSPORUM CANIS IN RABBITS
}

\author{
Fernanda Vasquez Daud*, Suely Mitoi Ykko Ueda, Alessandra Navarini, Lycia Mara Jenné Mímica \\ Faculdade de Ciências Médicas, Irmandade da Santa Casa de Misericórdia de São Paulo, São Paulo, SP, Brasil.
}

\begin{abstract}
The ozone is effective against most microorganisms due to its high oxidant power. Low concentrations and short-term contact are sufficient to inactivate bacteria, mold, yeast, parasites, seaweeds, protozoa and fungi. Microsporum canis is an important agent of dermatophitosis in human and animal. The aim of the current study was to assess the efficacy of ozonized oil over Microsporum canis in rabbits. Eighteen male New Zealand white rabbits, weight ranging from 2 to $3.2 \mathrm{~kg}$ were depilated in the cranial dorso-lateral and right caudal, and cranial and left caudal regions. The regions were inoculated with Microsporum canis, excepting the right caudal region, and were denominated TM, O, OM and M, respectively. After seven days, the treatment of lesions in TM began with $0.12 \mathrm{~g}$ of terbinaphine $1 \%$ cream; in $\mathrm{OM}$ and $\mathrm{O}$ with $0.12 \mathrm{~g}$ of ozonized oil; all animals were treated once a day for 28 days. Region M was not treated. Material was collected from those regions for cultivation in Sabouraud agar at day 28 of treatment. In the evolution of the treatment with terbinaphine, of 14 contaminated regions with Microsporum canis ten evolved to cure. With the ozonized oil, of 15 contaminations, four were cured. Clinically, that is, the macroscopic evaluation of lesions showed improvement in the TM and OM treated regions. We can conclude that there was statistical evidence of the protection action of the oil against the dermatophyte.
\end{abstract}

Key words: Fungi; Microsporum; Oils; Ozone; Rabbits.

\section{INTRODUCTION}

The fact that the ozone is a potent oxidant accounts for its high reactivity. This gas dissolves in the plasma, extracellular fluids, the thin layer of water which covers the skin and in regions coated by mucosa, triggering reactions with a number of molecules present in biological fluids, such as antioxidants, proteins, carbohydrates, and, mainly, with polyunsaturated fatty acids. By these reactions, reactive oxygen species (ROS) and lipid oxidation products (LOPs) are generated, both responsible for successive and multiple biochemical reactions that occur in different body cells (5).

The ozone in its gaseous or aqueous phases is effective against the majority of microorganisms tested by numerous research groups $(2,4,5,6,26)$. Low concentrations and shortterm contact are enough to inactivate bacteria, mold yeast, protozoa algae and fungi $(10,11,12,20)$. The mechanism of antimicrobial action occurs due to the membrane lysis of the agents, after the oxidation process (14). It is believed that the primary attack is against the cellular wall of the microorganism 
and, following, on penetrating the interior of cell, the ozone promotes oxidation of amino and nucleic acids. The cellular lysis depends on the extension of such reactions (25).

The ozonized olive oil has been currently used for topic treatments of wounds, anaerobic and herpes infections, ulcers and trophic burns, cellulite, abcesses, anal fissures, decubitus ulcers, fistules, furunculosis, gingivitis, vulvovaginitis, fungical illnesses (5, 23, 24) and epidermal infections (3). The antimicrobial activity of the ozonized sunflower oil has brought valuable contribution against bacteria, viruses and fungi (15, $16,17,21)$

Microsporum canis is an important agent of dermatophitosis in human and animal (7, 22). This worldly distributed canis variety is the most common zoophilia species in human infections. The lesions caused by this dermatophite are usually located on the skin and pelage and commonly cause tinea capitis and tinea corporis in children and adults who had contact with dogs or cats (mainly reservoirs), or infected children (13). In animals, while the dogs develop tegumentary lesions, the cats, otherwise, remains asymptomatic or shows tiny lesions; such peculiarity makes the cats a serious threat to the control of the microsporum dermatophitosis (7).

The aim of the present study was to assess the efficacy of the ozonized oil against Microsporum canis in rabbits.

\section{MATERIAL AND METHODS}

Eighteen male New Zealand white rabbits, weighing between 2 and $3.2 \mathrm{~kg}$ were used in this study. The animals were kept in the biotery of UTECE (Unity of Surgical Technique and Experimental Surgery of Irmandade da Santa Casa de Misericórdia de São Paulo), confined in individual cages under controlled temperature ( 15 to $20^{\circ} \mathrm{C}$ ), humidity of $55 \pm 10 \%$, and maintained under uniform circadian rhythm with lighting schedule of 12 hours (dark) and 12 hours (light). Food and water were offered ad libitum.

\section{After one week of adaptation, the animals were inoculated}

The Research Project has been approved by the Ethics in Animal Experimentation Committee of the Faculty of Medical
Sciences of Santa Casa de São Paulo, under protocol number 159, according to the "Guide for the Care and Use of Laboratory Animals" and "Ethical Principles in Animal Experimentation of the Brazilian College of Animal Experiments".

\section{Preparation of the inoculation broth}

For the culture broth, a sample of human scalp contaminated with a strain of Microsporum canis was collected (patient MMC - sample collected on 28/07/2008 in the Dermatology Service of Santa Casa de Misericórdia de São Paulo). That strain was cultivated in Sabouraud Agar and kept at room temperature until the growth of the fungus, in the Laboratory of Microbiology of Faculty of Medical Sciences of Santa Casa de São Paulo. The broth was prepared using $10 \mathrm{ml}$ of TSB (Tryptic Soy Broth) and inoculation of Microsporum canis at $10^{9} \mathrm{UFC} / \mathrm{ml}$ concentration.

\section{Inoculation}

The animals were tranquilized with an intramuscular injection of 2 to $2.5 \mathrm{ml}$ of acepromazine $0.2 \%, 15$ to 20 minutes prior to the procedure. Following, depilation in the four dorsal regions of the animals were performed: right dorso-lateral cranial and right caudal, and left dorso-lateral cranial and left caudal. An appropriate shearing machine and a number 40 blade (surgical) were used in order to obtain depilated places of around 36 square centimeters (Figure 1).

In the center of each square, a circumference of $2 \mathrm{~cm}$ diameter was delimited with permanent ink (Figure 2), followed by superficial scarification of the circumferences of the right dorso-lateral cranial, left dorso-lateral cranial, and left dorso-lateral caudal regions using a no. 22 scalpel blade. Subsequently, the three scarified regions underwent inoculation by a sterile swab embedded in Microsporum canis broth.

After the inoculations, the places were maintained uncovered and the animals were kept free in their cages. The right dorso-lateral caudal region did not undergo scarification or inoculation. It was only demarcated the place where the ozonized oil would be applied. 


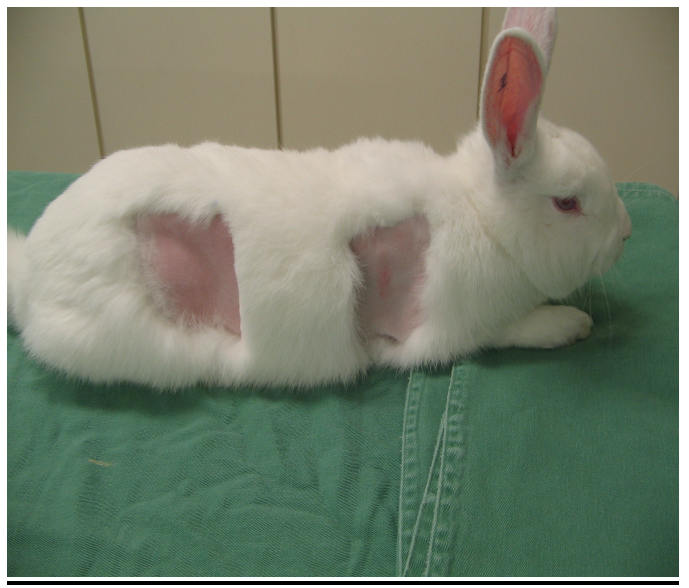

Figure 1. Preparation of the rabbit, with depilation of a $36 \mathrm{~cm}^{2}$ area in the right dorsolateral cranial region for subsequent inoculation using $M$. canis, and the right caudal region which was not scarified or inoculated.

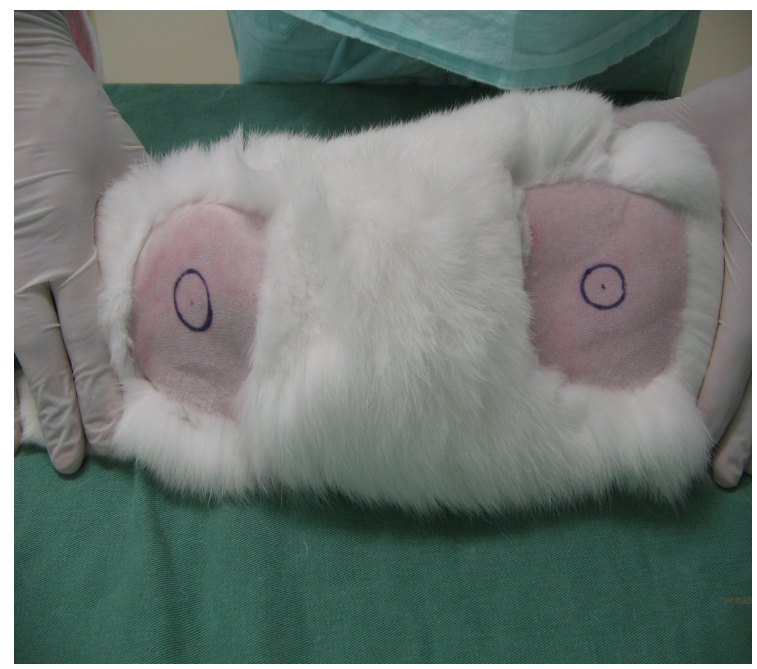

Figure 2. Left dorsolateral cranial and caudal regions of the rabbit, marked out centrally with a $2 \mathrm{~cm}$ circumference for subsequent scarification and inoculation using M. canis.

\section{Mycological examination}

The mycological examination was performed at days 0 (prior to inoculation) and 7, 14, 21 and 28 post-inoculation. The samples were collected from the regions through friction with a sterile swab, humidified with sterile saline solution. The material collected was kept in Stuart's medium until the cultivation of the material in Sabouraud agar. The plates were maintained at room temperature and analyzed, searching for growth of Microsporum canis. All plates were read at day 15 of cultivation.

\section{Treatment of the lesions}

The initial lesions, suggestive of dermatophitosis by Microsporum canis, were detected around days 5 to 7 postinoculation and were confirmed through culture of the suspect material. The treatment of the lesions began at day 7 postinoculation and the regions were standardized and identified for treatment as follows:

- right dorso-lateral cranial region - treated once a day with $0.12 \mathrm{~g}$ of terbinaphine $1 \%$ cream, for 28 days denominated TM region (terbinaphine and Microsporum canis);

- Right dorso-lateral caudal region - treated once a day with $0.12 \mathrm{~g}$ of ozonized oil, for 28 days - denominated $\mathrm{O}$ region (ozonized oil);

- left dorso-lateral cranial region - treated once a day with $0.12 \mathrm{~g}$ of ozonized oil, for 28 days - denominated OM region (ozonized oil and Microsporum canis);

- left dorso-lateral caudal region - no treatment received and region monitored for 28 days - denominated $\mathrm{M}$ region (Microsporum canis).

Precision scales were used daily (Denver Instrument Company AA-200) to weigh the medication.

\section{Ozonized oil}

The ozonized oil Bioperoxoil®, originally from Barcelona, Spain, was used for the treatment of regions $\mathrm{O}$ and OM.

\section{Statistical methodology}

To assess the qualitative variables, the oucomes were presented through absolute and relative frequencies. These analyses were performed using the McNemar Test. It was established the significance level of $5 \%$.

Resume measurements were calculated for the quantitative variables. The comparison between the quantitative variables was performed using the Paired t Test. The significance level was established at $5 \%$. 


\section{RESULTS}

Twenty-eight days after the onset of the treatment, the actions of the terbinaphine $1 \%$ cream and the ozonized oil were equivalent (Table 1).

The individual evolution of each treatment is shown in Tables 2 and 3. The regions treated with the ozonized oil (OM) and the non-treated areas are shown in Table 4, whereas the regions treated (TM) and non-treated with terbinaphine $1 \%$ cream are in Table 5.

It is noteworthy that the statistical analysis of Tables 4 and
5 was not possible, since all $\mathrm{M}$ regions were contaminated at the end of the study.

As regards the clinical evaluation of the regions, Figures 3A, $\mathrm{B}$ and $\mathrm{C}$, representing regions $\mathrm{TM}, \mathrm{OM}$ and $\mathrm{M}$, respectively, show lesions formed at week 1 post-inoculation with Microsporum canis. Figure 4 shows the evolution of lesion (Figure 3A) treated with terbinaphine $1 \%$ cream for 21 days. Figure 5 refers to the treatment of lesion of figure $3 \mathrm{~B}$ with ozonized oil for 21 days. Finally, Figure 6 shows the initial lesion (Figure 3C) without any treatment, after 21 days.

Table 1. Comparison between treatments with ozonized oil and terbinaphine $1 \%$ cream at the end of treatment.

\begin{tabular}{lcccc}
\hline \multirow{2}{*}{ OM $_{\text {end }}$} & & \multicolumn{2}{c}{ TM $_{\text {end }}$} & Total \\
\cline { 3 - 4 } Non- contaminated & $\mathrm{n}$ & Non- contaminated & Contaminated & \\
\hline \multirow{2}{*}{ Contaminated } & $\%$ & 4 & 3 & 7 \\
& $\mathrm{n}$ & 57.1 & 42.9 & 100.0 \\
\hline \multirow{2}{*}{ Total } & $\%$ & 8 & 3 & 11 \\
& $\mathrm{n}$ & 72.7 & 27.3 & 100.0 \\
\hline $\mathrm{p}=0.227$ & $\%$ & 12 & 63.3 & 18 \\
\hline
\end{tabular}

$\mathrm{p}=0.227$

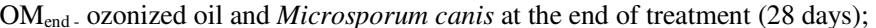

$\mathrm{TM}_{\mathrm{end}}$ - terbinaphine cream and Microsporum canis at the end of treatment (28 days).

Table 2. Comparison between treatment with terbinaphine $1 \%$ at the initial moment ( 7 days of inoculation) and at the end of treatment.

\begin{tabular}{lcccc}
\hline \multirow{2}{*}{ TM $_{\text {initial }}$} & & \multicolumn{2}{c}{ TM $_{\text {end }}$} & \multirow{2}{*}{ Total } \\
\cline { 3 - 4 } & & Non- contaminated & Contaminated & \\
\hline \multirow{2}{*}{ Non- contaminated } & $\mathrm{n}$ & 2 & 2 & 4 \\
& $\%$ & 50.0 & 50.0 & 100.0 \\
\hline \multirow{2}{*}{ Contaminated } & $\mathrm{n}$ & 10 & 4 & 14 \\
& $\%$ & 71.4 & 28.6 & 100.0 \\
\hline \multirow{2}{*}{ Total } & $\mathrm{n}$ & 12 & 6 & 18 \\
& $\%$ & 66.7 & 33.3 & 100.0
\end{tabular}

$\mathrm{p}=0.039$

$\mathrm{TM}_{\text {initial }}$ - terbinaphine cream and Microsporum canis at the initial moment;

$\mathrm{TM}_{\mathrm{end}}$ - terbinaphine cream and Microsporum canis at the end of treatment (28 days). 
Table 3. Comparison between treatment with ozonized oil at the initial moment ( 7 days of inoculation) and at the end of treatment.

\begin{tabular}{lcccc}
\hline \multirow{2}{*}{ OM $_{\text {initial }}$} & & \multicolumn{2}{c}{ OM $_{\text {end }}$} & \multirow{2}{*}{ Total } \\
\cline { 3 - 5 } & & Non- contaminated & Contaminated & \\
\hline \multirow{2}{*}{ Non- contaminated } & $\mathrm{n}$ & 3 & 0 & 3 \\
& $\%$ & 100.0 & 0.0 & 100.0 \\
\hline \multirow{2}{*}{ Contaminated } & $\mathrm{n}$ & 4 & 11 & 15 \\
& $\%$ & 26.7 & 73.3 & 100.0 \\
\hline \multirow{2}{*}{ Total } & $\mathrm{n}$ & 7 & 11 & 18 \\
& $\%$ & 38.9 & 61.1 & 100.0 \\
\hline
\end{tabular}

$\mathrm{p}=0.125$

$\mathrm{OM}_{\text {initial }}$ - ozonized oil and Microsporum canis at the inicial moment;

$\mathrm{OM}_{\mathrm{end}}$ - ozonized oil and Microsporum canis at the end of treatment (28 dias).

Table 4. Comparison between areas treated with ozonized oil (OM) and non-treated areas at the final moment.

\begin{tabular}{lccc}
\hline \multirow{2}{*}{ OM $_{\text {end }}$} & & $\mathbf{M}_{\text {end }}$ & Total \\
\cline { 3 - 3 } & & Contaminated & \\
\hline Non- contaminated & $\mathrm{n}$ & 7 & 7 \\
& $\%$ & 100.0 & 100.0 \\
\cline { 2 - 3 } Contaminated & $\mathrm{n}$ & 11 & 11 \\
& $\%$ & 100.0 & 100.0 \\
\hline \multirow{2}{*}{ Total } & $\mathrm{n}$ & 18 & 18 \\
& $\%$ & 100.0 & 100.0
\end{tabular}

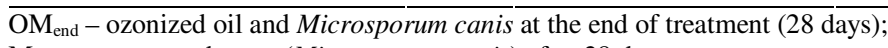

$\mathrm{M}_{\text {end }}$ - non-treated areas (Microsporum canis) after 28 days.

Table 5. Final comparison between areas treated with terbinaphine $1 \%$ cream (TM) and non-treated areas (M).

\begin{tabular}{lccc}
\hline \multirow{2}{*}{ TM $_{\text {end }}$} & & $\mathbf{M}_{\text {end }}$ & Total \\
\cline { 3 - 3 } & & Contaminated & \\
\hline \multirow{2}{*}{ Non- contaminated } & $\mathrm{n}$ & 12 & 12 \\
& $\%$ & 100.0 & 100.0 \\
\cline { 2 - 3 } Contaminated & $\mathrm{n}$ & 6 & 6 \\
& $\%$ & 100.0 & 100.0 \\
\hline \multirow{2}{*}{ Total } & $\mathrm{n}$ & 18 & 18 \\
& $\%$ & 100.0 & 100.0 \\
\hline
\end{tabular}

$\mathrm{TM}_{\mathrm{end}}$ - terbinaphine cream and Microsporum canis at the end of treatment ( 28 days);

$\mathrm{M}_{\mathrm{end}}$ - non-treated areas (Microsporum canis) after 28 days. 


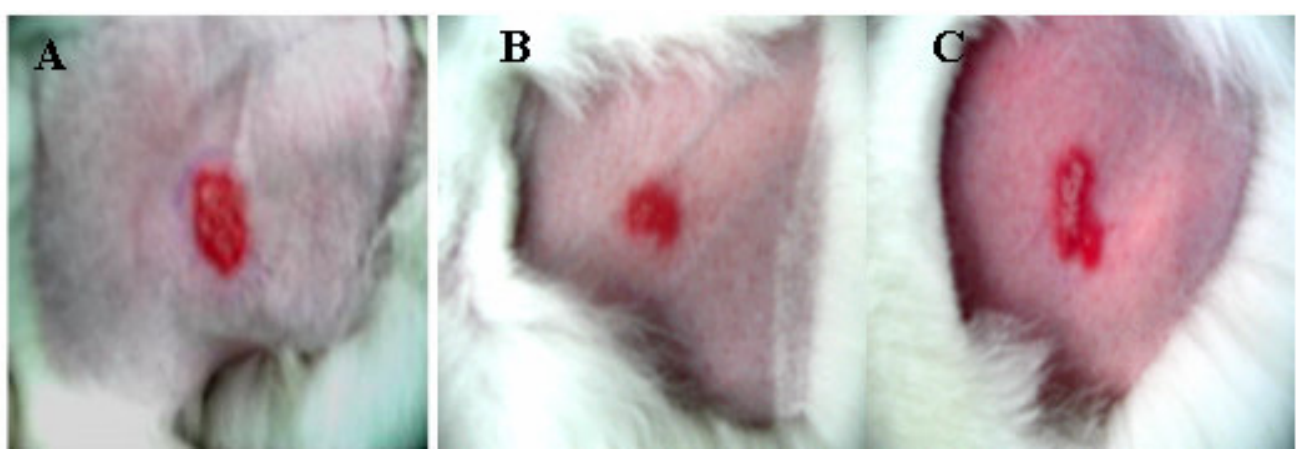

Figure 3. A. TM region seven days post-inoculation using $M$. canis, revealing marked erythematous area and slight desquamation of the lesion, B. OM region seven days post-inoculation using M. canis, revealing marked erythema, C. M region seven days post-inoculation showing marked erythema and slight desquamation of the lesion.

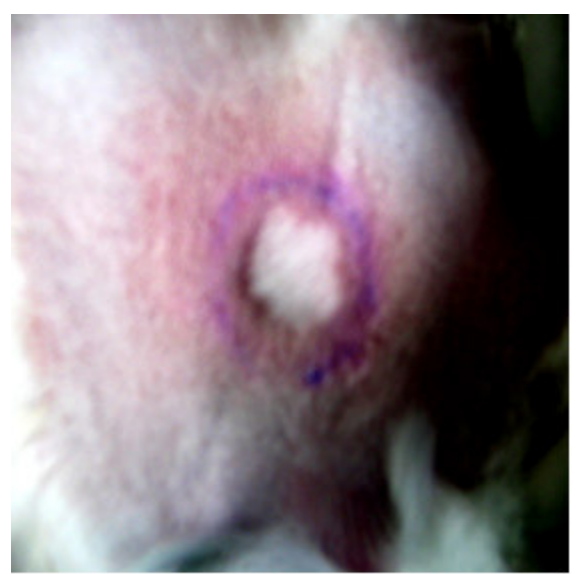

Figure 4. TM region 21 days after treatment with terbinafine cream, evidencing local hair regrowth and absence of erythema or desquamation.

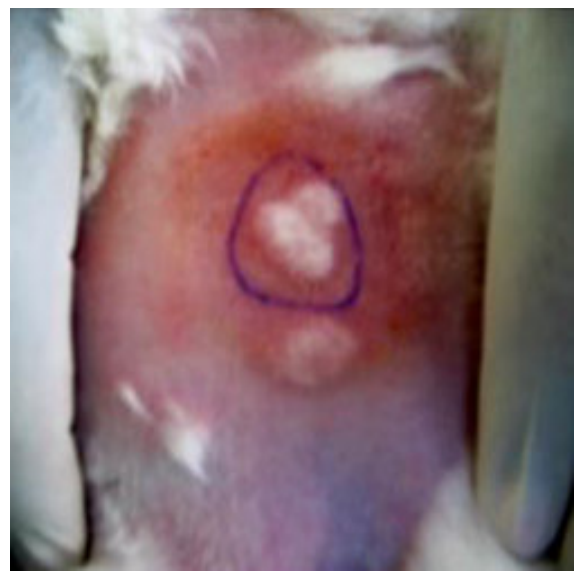

Figure 5. OM region 21 days after treatment with ozonized oil showing hair regrowth, absence of erythema or desquamation, and slight yellowish coloration due to accumulation of oil following a series of daily applications of the product.

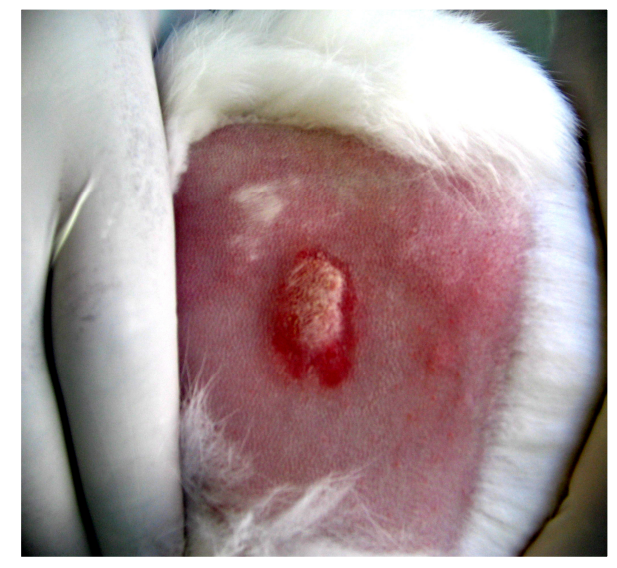

Figure 6. $M$ region after 21 days without treatment evidencing marked erythema, absence of hair regrowth and formation of crust over lesion.

\section{DISCUSSION}

The statistical evaluation of data shows that the action of the ozonized oil and terbinaphine cream was similar (Table 1). However, the individual evolution of each treatment was different (Tables 2 and 3), evidencing that the terbinaphine cream was more efficient in the fungus elimination, and also that there were signs of the action of the ozonized oil against Microsporum canis.

The comparisons among the treated regions, both with ozonized oil and terbinaphine cream, and the non-treated regions (Tables 4 and 5) show that the treatment with either therapy brought positive results, since the non-treated regions 
were all infected by the fungus in the final evaluation at day 28.

There was clinical evidence of improvement of the lesions treated with either products (Figures 4 and 5). The daily observation revealed a fast improvement of the lesion with the use of terbinaphine cream (Figure 4). Although the areas treated with ozonized oil also showed improvement (Figure 5), it was a slower process if compared with the treatment with terbinaphine. The latter showed clear reduction in erythema, gradual repilation of the affected places and a reduction in the scaly and encrusted areas. In the non-treated areas, hyperemic portions lasted longer and there were more intense encrusted and scaly areas.

The imbalance between the scarcity of articles related to the use of ozonized oil in the treatment of fungical illnesses and the more abundant studies on its germicide activitiy over bacteria $(1,8,21)$ draws attention and causes surprise, since there is a large number of concordant studies in the literature regarding the ozone as a fungical product $(15,16)$. The mechanism of action seems to be related to the diffusion of the ozone through the fungical wall and into the interior of the cytoplasm breaking, this way, the vital cellular function. The cellular wall seems to be a possible site of oxidative inactivation of the ozone (23).

Some works found good outcomes from ozonized oil over certain fungi. One study, comprising 257 patients with foot lesions characteristic of epidermophitosis, consisted of a treatment with twice-daily topic application of the oil onto the affected areas. This treatment accomplished a rate of $88.3 \%$ of clinical cure in 227 patients, the highest cure rate for scaly epidermophitosis (17). The efficacy of the ozonized sunflower oil was also evaluated in 200 patients for the treatment of tinea pedis, in comparison with the use of ketoconazole $2 \%$. Total clinical and mycological cure was accomplished in $75 \%$ and $81 \%$ of cases treated with Oleozon ${ }^{\circledR}$ and ketoconazole, respectively, with no significant differences between the two groups. The authors of that study regard the ozonized oil as an effective and low-cost antimycotic drug (18).

Two case reports show the efficacy of ozonized oil against onicomicosys in human patients infected by Trichophyton beigelli and T. rubrum, respectively. The product was applied twice a day and, subsequently, the affected area covered with PVC. The clinical and mycological cure occurred in 90 days (9).

In the current experiment, particular attention was paid to the growth or non-growth of Microsporum canis in the mycological studies. There was no intention to clarify whether the ozonized oil has a fungistatic effect; nevertheless, if it does, this data may account for the fact that the clinical improvement of lesions with the oil was slower in comparison with the use of terbinaphine, a well-proven fungicide product (19).

In conclusion, according to the present study, there is statistical indication that the ozonized oil acts against Microsporum canis and there is clinical evidence of its action over this dermatophyte.

\section{ACKNOWLEDGMENT}

To FAPESP (Fundação de Amparo à Pesquisa do Estado de São Paulo) for funding this research; Faculty of Medical Sciences of Santa Casa de São Paulo and Irmandade da Santa Casa de Misericórdia de São Paulo for providing institutional support to the development of this project. To Cláudia Catelani Cardoso, Veterinarian, Doctorate in Chemotherapy by the Department of Pharmacology of University of Milan, Italy, for sharing her knowledge in ozonotherapy.

\section{REFERÊNCIAS}

1. Abreu, J.M.; Sardinas, M.A. (2005). Oleozón em el tratamiento de la periodontitis simples moderada. Rev. Medica. Electron. 27(3). [http://www.revmatanzas.sld.cu/revista\%20medica/ano\%202005/vol3\%2 02005/tema03.htm

2. Almeida, E.S.; Assalin, M.R.; Rosa, M.A.; Durán, N. (2004). Tratamento de efluentes industriais por processos oxidativos na presença de ozônio. Quim. Nova. 27(2), 818-824.

3. Alvarez, M.; O’Brien, R.T. (1982). Mechanisms of inactivation of poliovirus by chlorine dioxide and iodine. Appl. Environ. Microbiol. 44, 1064-1071.

4. Block, S.S. (1991). Desinfection, sterilization and preservation. Lea \& Febiger, Philadelphia, PA. 
5. Bocci, V. (2005). A new medical drug. Springer, Norwel.

6. Cardoso, C.C.; Veiga, S.M.O.M.; Nascimento, L.C.; Fiorini, J.E.; Amaral, L.A. (2003). Avaliação microbiológica de um processo de saniticação de galões de água com a utilização do ozônio. Ciênc. Tecnol. Aliment. (Campinas). 23(1), 59-61.

7. Castro, R.M.; Fischman, O.; Talarico, F.OS.; Lau, D. (1976). Epizootia por Microsporum canis em perros de raza San Bernardo. Castellania, 4(11), 215-217.

8. Guerra, O.C.; Cepero M.S.; Jordan, M.E.M.; Vazquez, T.C. (1997). Aplicación de la ozonoterapia en el tratamiento de la alveolitis. Rev. Cuba. Estomatol. 34(1), 21-24.

9. Guerrer, L.V.; Cardoso, C.C.; Cunha, K.C.; Almeida, M.T.G. (2007). Avaliação da atividade antimicrobiana "in vitro" do óleo ozonizado (Bioperoxoil@) frente a leveduras isoladas de onicomicose. In: $11^{\circ} \mathrm{ECIF}$ Encontro Científico da FAMERP \& $4^{\circ}$ IV CAIC - Congresso Anual de Iniciação Científica Pavilhão Fleury; São José do Rio Preto, Faculdade de Medicina de São José do Rio Preto; 2007. [Pôster - R037].

10. Higa, D.R.; Cese, P.C.; Falcão, R.M.M.; Chacha-Cese, A.; Borges, F.S.; Madeira-Oliveira, J. (2007). Efeito do gerador de alta frequência sobre cultura de Candida tropicalis. Rev Esp Fisiot.1, 1-2.

11. Jorge, R.A.; Rodriguez, Y.L.; Rodriguez, A.C.; Ruiz, J.A. (2006). Producción científica sobre aplicaciones terapêuticas del ozono em el Web of Science. ACIMED; http://scielo.sld.cu/scielo.php?script =sci_arttext\&pid=S1024-94352006000100007\&lng=pt\&nrm=iso/ 14(1).

12. Kim, J.G.; Yousef, A.E.; Dave, S. (1999). Application of ozone for enhancing the microbiological safety and quality of foods: a review. $J$. Food. Prot. 62(9), 1071-1087.

13. Lacaz, C.S.; Porto, E.; Martins, J.E.C.; Heins-Vaccari, E.M.; Melo, N.T. (2002). Tratado de micologia médica Lacaz. Sarvier, São Paulo.

14. Lake, J.C.; Felberg, S.; Malavazzi, G.R.; Goulart, D.A.; Dantas, M.C.N.; Dantas, P.E.C. (2004). Efeito terapêutico da aplicação intra-ocular de ozônio em modelo experimental de endoftalmite por Staphylococcus epidermidis em coelhos. Arq. Brás. Oftalmol. 67(4): 575-579.

15. Lezcano, I.; Molerio, J.; Gómez, M.; Contreras, R.; Roura, G.; Díaz, W. (1998). Actividad in vitro del oleozon frente a agentes etiológicos de infecciones de la piel. Rev. CENIC. Cienc. Biol. 28, 105-109.

16. Lezcano, I.; Núñez, N.; Gutiérrez, M.; Molerio, J.; Regüeiferos, M.; Diaz, W. (1996). Actividad in vitro del aceite de girasol ozonizado OLEOZON frente a diferentes especies bacterianas. Rev. CENIC, C. Biol. 27(1-3), 46-49.

17. Lincheta, F.L.; Simon, R.D.; Cepero, S.M.; Diaz, L.N.; Duque, S.M. (2000). Solución para la epidermofitosis de los pies en integrantes de las Fuerzas Armadas Revolucionarias. Rev. Cuba. Méd. Mil. 29(2), 98-102.

18. Menendez, S.; Falcon, L.; Simon, D.R.; Landa, N. (2002). Efficacy of ozonized sunflower oil in the treatment of tinea pedis. Mycoses. 45(8), 329-32.

19. Petranyi, G.; Meingassner, J.G.; Mieth, H. (1987). Activity of terbinafine in experimental fungal infections of laboratory animals. Antimicrob. Agents. Chemother. 31(10), 1558-1561.

20. Scrollavezza, P.; Ablondi, M.; Pogliacomi, B.; Guareschi, D.; Dall Aglio, R.; Poldi, R.; Pezzoli, G. (1997). Ozone treatment in mastits, metrits and retention of fetal membranes in the dairy cow. $2^{\text {ed }}$ Congresso Internacional do Ozônio, Havana. Anais. Havana: Departamiento de Publicaciones, p. 17-21.

21. Sechi, L.A.; Lezcano, I.; Nunez, N.; Espim, M.; Dupre, I.; Pinna, A.; Molicotti, P.; Fadda, G.; Zanetti, S. (2001). Antibacterial activity of ozonized sunflower oil (Oleozon). J. Appl. Microbiol. 90(2), 279-284.

22. Severo, L.C.; Ferreiro, L. (1985). Segundo caso de infecção por Microsporum canis em equino no Rio Grande do Sul e no Brasil. Arq. Fac. Vet. UFRGS. 13, 65-70.

23. Sunnen G.V. (1988). Ozone in Medicine: Overview and Future Directions. J. Adv. Med. 1(3), 159-174.

24. Valacchi, G.; Fortino, V.; Bocci, V. (2005). The dual action of ozone on the skin. Br. J. Dermatol. 153(6), 1096-1100.

25. Velano, H.E.; Nascimento, L.C.; Barros, L.M.; Panzeri, H. (2001). Avaliação in vitro da atividade antibacteriana da água ozonizada frente ao Staphylococcus aureus. Pesqui. Odontol. Bras. 15(1), 18-22.

26. Warshaw, L.J. (1953). Bactericidal and fungicidal effects of ozone on deliberately contaminated 3-D viewers. Am. J. Public. Health. Nations. Health. 43, 1558-1562. 